\title{
Teachers' knowledge on Educational Speech-Language-Hearing Pathology and the relevance of communication to learning
}

\author{
Jéssica Katarina Olímpia de Melo' \\ https://orcid.org/0000-0003-1699-5957 \\ Cleide Fernandes Teixeira ${ }^{1}$ \\ https://orcid.org/0000-0001-9869-4431 \\ Bianca Arruda Manchester de Queiroga ${ }^{1}$ \\ https://orcid.org/0000-0001-5081-924X
}

Universidade Federal de Pernambuco, Recife, Pernambuco, Brasil.

Conflict of interests: Nonexistent

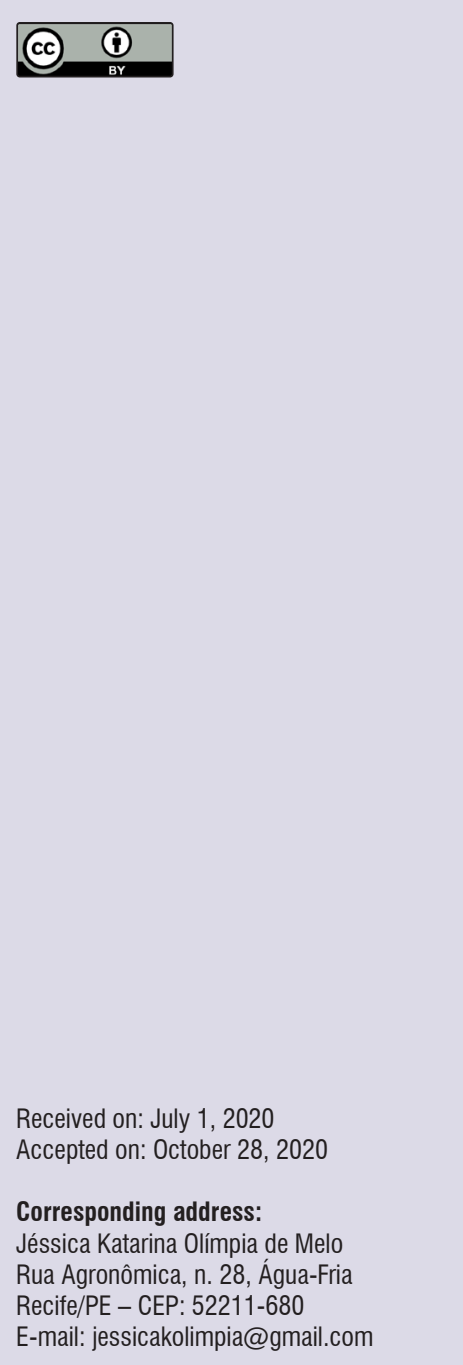

\section{ABSTRACT}

Purpose: to investigate the teachers' knowledge on educational speech-languagehearing pathology and the importance of auditory and linguistic skills to learning, comparing the answers of public-school teachers with those of private ones.

Methods: an exploratory study with a mixed quantitative and qualitative approach, conducted with 25 teachers working in kindergarten and elementary school. Data were collected with a questionnaire comprising 19 closed-ended questions (which dealt with the relationship between language, hearing, and learning) and one open-ended question (which approached their knowledge on educational speech-language-hearing pathology. The quantitative data were analyzed with descriptive and inferential statistical analyses, and the qualitative ones, with theme modality content analysis.

Results: in general, the teachers recognize the importance of hearing and language to learning, although they do not feel prepared to deal with it at school, neither do they have more specific knowledge of auditory processing. The results obtained in the open-ended question revealed an also limited knowledge on educational speech-language-hearing pathology. In this sense, their greatest source of information was some teachers' previous experience with the work of a speech-language-hearing pathologist within the educational setting. No important differences were observed between the answers given by public school teachers and those by private ones.

Conclusion: the teachers' knowledge on educational speech-language-hearing pathology and the importance of hearing and language to learning is still limited, which requires more investment in the training in this field.

Keywords: Learning; Language; Audiology; Education 


\section{INTRODUCTION}

Education is a responsibility that oftentimes is given to the school alone, particularly to the teacher'. However, all those social institutions in the fields of health and education that are committed to child development are expected to make part of it ${ }^{2}$. The Speech-language-hearing sciences, for instance, involve specific knowledge on auditory development, language acquisition, and so forth, which interfaces with education itself.

In Brazil, educational speech-language-hearing pathology was recognized as a specialty in $2010^{3}$. It is a broad and highly important field encompassing from kindergarten to adult education ${ }^{4}$. The work of speechlanguage-hearing pathologists in schools must not be related to clinical practice. However, their participation enables professionals to be attentive and ready to identify different changes as early as possible ${ }^{5}$.

Considering that a child's early years are utterly important to their auditory skills and language development ${ }^{4}$, the teachers must know about the development of communication-related aspects for them to facilitate such a process. This is the peak period for neuronal plasticity and central auditory system maturation $^{6}$. Also, as language is acquired, the child starts to access the symbolic system of meanings - a resource that allows the experience to become knowledge.

According to the National Literacy Plan ${ }^{7}$, children are expected to have learned to read and write by the end of third grade to keep their future studies from being impaired. However, learning to read and write requires, among other aspects, that the visual and auditory perception mechanisms be stimulated ${ }^{8}$. Yet, teachers do not always know how to proceed, neither do they have access to the necessary resources for such development. Hence, the speech-language-hearing pathologist can work in an educational setting along with the faculty to define strategies to further learning and improve reading and writing patterns ${ }^{4-9}$.

Recent research, conducted to map the work of educational speech-language-hearing pathologists in Brazil $^{4}$, highlights that most of these professionals work in kindergarten and elementary school. This may be explained by the concern with the first years at school, as the proper stimulation in the initial phase of life (up to six years old) plays an important role in the child's future acquisitions. Thus, the multidisciplinary cooperation between speech-language-hearing pathologists and teachers is responsible for contributing not only to the child's personal benefit but also that of the whole school community.

Nevertheless, due to the long-time scarce investment of the Speech-Language-Hearing Sciences in the field of education, it may be that teachers are completely or partially unfamiliar with the true role of Educational Speech-Language-Hearing Pathology. Given the above, this study aimed to investigate the teachers' knowledge on Educational Speech-Language-Hearing Pathology and the importance of the auditory and linguistic skills to learning, by comparing the answers of public and private school teachers.

\section{METHODS}

The study was approved by the Ethics Committee of the Department of Health Sciences at the Universidade Federal de Pernambuco, Brazil, under evaluation report number 2.776.568, in 2018. This is an exploratory study with a mixed quantitative and qualitative approach. The participating schools were selected by convenience. As inclusion criteria, teachers had to be teaching in either kindergarten or elementary school in the municipal public or private school system in the city of Recife, Pernambuco, Brazil, besides formally consenting on their participation in the study. Altogether, 25 teachers participated in the study - 15 from the public, and 10 from the private system. The collection was made in September and October 2018. Recife does not have speech-language-hearing pathologists working in the Municipal Department of Education, and their inclusion in private schools is still limited - none of the schools participating in this study had this professional in their staff.

Data were collected with a questionnaire developed in the continuing education course for teachers and coordinators of the Municipal School System of Recife. It comprises 19 closed-ended questions - three on the teachers' professional training profile and the other 16 on the relationship between language, hearing, and learning. Besides these, there was also an open-ended question, that read as follows: "Have you ever heard of Educational Speech-Language-Hearing Pathology? What do you know about it?".

The interviews were individually conducted on the schools' premises, after informing them about the confidentiality of the information, and the procedures and relevance of the research. Each interview lasted 30 minutes at the most. The results regarding the 
profile of the sample and the answers to the questionnaire's closed-ended questions were tabulated, categorized, and presented as descriptive statistics (absolute frequency). The answers of public-school teachers were compared with those of private ones with the chi-squared test, considering the 95\% confidence interval and the $(p<0.05)$ significance level. As for the open-ended question, a content analysis was conducted with the theme modality proposed by Bardin $^{10}$.

\section{RESULTS}

The profile of the teachers that participated in the study regarding their age, postgraduate studies, and time since graduation is presented in Table 1.

Table 1. Professional training profile of the interviewed teachers. Recife, Pernambuco, Brazil, 2018.

\begin{tabular}{|c|c|c|c|c|}
\hline & \multicolumn{2}{|c|}{ Public School } & \multicolumn{2}{|c|}{ Private School } \\
\hline & \multicolumn{2}{|c|}{ Frequency } & \multicolumn{2}{|c|}{ Frequency } \\
\hline & $\mathbf{N}^{\circ}$ & $\%$ & $\mathbf{N}$ & $\%$ \\
\hline \multicolumn{5}{|l|}{ Age group } \\
\hline 28 - 40 years & 4 & 26.67 & 4 & 40 \\
\hline $41-50$ years & 8 & 53.33 & 5 & 50 \\
\hline 50 - 60 years & 2 & 13.33 & & \\
\hline$\geq 60$ years & 1 & 6.67 & 1 & 10 \\
\hline \multicolumn{5}{|c|}{ Postgraduate studies } \\
\hline Specialization & 13 & 86.67 & 5 & 50 \\
\hline Master's degree & 2 & 13.33 & 1 & 10 \\
\hline Doctor's degree & & & 1 & 10 \\
\hline No postgraduate & & & 3 & 30 \\
\hline \multicolumn{5}{|c|}{ Time since graduation } \\
\hline $1-5$ years & & & 1 & 10 \\
\hline $6-12$ years & 5 & 33.33 & 4 & 40 \\
\hline $13-20$ years & 4 & 26.67 & 2 & 20 \\
\hline 21 - 26 years & 4 & 26.67 & 1 & 10 \\
\hline$\geq 26$ years & 2 & 13.33 & 2 & 20 \\
\hline
\end{tabular}

Most teachers were over 40 years old (68\%), having graduated from college more than five years before. It is inferred from these aspects that this sample is experienced in education. Concerning their postgraduate studies, specialization is the predominant choice.
The results of the teachers' answers to the closedended questions are presented below in Table 2. To describe and compare the results, the difference between the answers of public and private school teachers is shown in the distribution of answers. 
Table 2. Distribution of the teachers' answers to the questionnaire. Recife, Pernambuco, Brazil, 2018

\begin{tabular}{|c|c|c|c|c|c|}
\hline \multirow{3}{*}{ Questions Assessed } & \multicolumn{2}{|c|}{ Private School } & \multicolumn{2}{|c|}{ Public School } & \multirow{3}{*}{ p-valor } \\
\hline & Yes & No & Yes & No & \\
\hline & $\mathrm{N}$ & $\mathbf{N}$ & $\mathbf{N}$ & $\mathbf{N}$ & \\
\hline $\begin{array}{l}\text { 1. Does knowing the auditory system help to understand sound } \\
\text { information processing? }\end{array}$ & 10 & & 15 & & - \\
\hline $\begin{array}{l}\text { 2. Do you know the audiometric configuration represented by the } \\
\text { speech banana? }\end{array}$ & 1 & 9 & 2 & 13 & .802 \\
\hline $\begin{array}{l}\text { 3. Do you know the auditory skills attributed to the central auditory } \\
\text { system? }\end{array}$ & 1 & 9 & 4 & 11 & 1.000 \\
\hline $\begin{array}{l}\text { 4. Did you know that the auditory processing in the left hemisphere is } \\
\text { different from that in the right one? }\end{array}$ & 7 & 3 & 5 & 10 & .072 \\
\hline $\begin{array}{l}\text { 5. Do you know what difficulties may be associated with the auditory } \\
\text { processing disorder? }\end{array}$ & 6 & 4 & 11 & 4 & .484 \\
\hline $\begin{array}{l}\text { 6. Did you know the effects of the central nervous system pathological } \\
\text { mechanisms can affect central functions? }\end{array}$ & 5 & 5 & 7 & 8 & .234 \\
\hline $\begin{array}{l}\text { 7. Did you know the effects of the central nervous system pathological } \\
\text { mechanisms can directly affect central functions in the brain? }\end{array}$ & 10 & & 9 & 6 & $* \star \star .022$ \\
\hline $\begin{array}{l}\text { 8. Did you know some skills can be assessed with specific auditory } \\
\text { tests? }\end{array}$ & 7 & 3 & 10 & 5 & .861 \\
\hline $\begin{array}{l}\text { 9. Do you believe language development can influence learning to read } \\
\text { and write? }\end{array}$ & 10 & & 15 & & - \\
\hline $\begin{array}{l}\text { 10. Do you usually observe and register the aspects that refer to your } \\
\text { students' speech and language? }\end{array}$ & 9 & 1 & 14 & 1 & .763 \\
\hline $\begin{array}{l}\text { 11. Do you feel prepared to observe your students' speech and } \\
\text { language aspects? }\end{array}$ & 5 & 5 & 6 & 9 & .622 \\
\hline $\begin{array}{l}\text { 12. Do you usually refer students with speech or language problems to } \\
\text { a specialist? }\end{array}$ & 6 & 4 & 12 & 3 & .115 \\
\hline $\begin{array}{l}\text { 13. Does knowing about hearing and language help teachers detect } \\
\text { students with learning problems? }\end{array}$ & 10 & & & 15 & - \\
\hline $\begin{array}{l}\text { 14.Do you consider it important to know tools that would help you } \\
\text { identify signs of learning problems? }\end{array}$ & 10 & & & 15 & - \\
\hline $\begin{array}{l}\text { 15. Do you consider it important that teachers be able to early identify } \\
\text { children with signs of learning disorder? }\end{array}$ & 9 & 1 & 14 & 1 & .763 \\
\hline $\begin{array}{l}\text { 16.Do you consider it important that teachers be prepared to identify } \\
\text { signs of hearing and language problems? }\end{array}$ & 9 & 1 & 14 & 1 & .763 \\
\hline
\end{tabular}

*** Statistically significant with the chi-squared test. The significance level used was $5 \%(p \leq 0.05)$. n: absolute frequency.

In general, there were no significant differences between the answers of public and private school teachers, except for question 7 . This question requires greater technical knowledge of the functioning of the central nervous system - hence, a significant difference was perceived between the answers $(p<.05)$, as none of the private school teachers answered with a "no".

All the teachers (100\%) answered with a "yes" to question 1, 9, 13, and 14 -which in general ask about the importance of the knowledge about the fields of hearing, language, and learning, as well as the importance of the teacher being equipped to identify problems in these fields, thus recognizing the importance of such knowledge for their work. Moreover, questions 15 and 16 also approach the issue of the teacher being prepared to deal with these problems to which only two teachers (one from a public school and the other from a private school) gave a negative answer. Based on these answers, it is safe to state that the teachers recognize this topic's importance to their work.

Questions 10 and 11 must also be highlighted. In question 10 , most of the teachers (96\%) of both schools reported they usually observe and register the 
students' speech and language aspects. However, in question 11 , most of them (56\%) stated they do not feel ready to carry out such activity. Some more specific questions on the auditory processing (questions 2, 3, $4,5,6$, and 8) reveal a range of answers between "yes" and "no", showing that teachers do not have in-depth knowledge of the topic. Lastly, question 12 reveals that most $(72 \%)$ of the teachers normally refer the children that have speech or language problems to a specialist (in general, a health professional).

Table 3 , in its turn, shows what language-related pathologies the teachers most often find in the classroom, as well as their frequency and relationship to reading and writing development.

Table 3. Frequency of language disorders observed in the classroom and relationship with learning. Recife, Pernambuco, Brazil, 2018

\begin{tabular}{lcc}
\hline Detailed answers to questions 17, 18, and 19 & N & $\%$ \\
\hline 17. Of the language pathologies and other problems listed below, check the ones you observe most & \\
frequently in your classroom routine. & 14 & 56 \\
- Stuttering & 21 & 84 \\
- Phonetic/phonological disorders & 13 & 52 \\
- Language delays & 10 & 40 \\
- Limited vocabulary & 9 & 36 \\
- Difficulty to carry out a dialogue/conversation & 9 & 36 \\
- Difficulty to tell a story or personal experience & \\
\hline 18. How often do you observe these problems in your classroom & 21 & 84 \\
- In less than 30\% of the students & 3 & 12 \\
- From 31 to $60 \%$ of the students & - & - \\
- In more than 61\% of the students &
\end{tabular}

19. Of the language pathologies, which ones do you believe are most related to problems with learning to read and write

- Stuttering

- Phonetic/phonological disorders (speech sound errors)

- Language delays

- Limited vocabulary

- Difficulty to carry out a dialogue /conversation

- Difficulty to tell a story or personal experience

$\begin{array}{cc}10 & 40 \\ 18 & 72 \\ 14 & 56 \\ 11 & 44 \\ 4 & 16 \\ 7 & 28\end{array}$

It is verified in Table 3 that the phonetic/phonological disorders are the most observed ones in the classroom, followed by stuttering and language delays. For the interviewed teachers, the phonetic/phonological disorders are the most related ones to problems with learning to read and write.

The content analysis of the answers given by the teachers to the open-ended question revealed five theme categories that demonstrate their knowledge of Educational Speech-Language-Hearing Pathology: 1) Teachers who believe they know the educational speech-language-hearing pathologist's work; 2)
Teachers who acknowledge they know little or in part the educational speech-language-hearing pathologist's work; 3) Teachers who know and/or have already had some experience with the educational speechlanguage-hearing pathologist's work; 4) Teachers that do not know educational speech-language-hearing pathology; 5) Teachers that have already had some experience with clinical speech-language-hearing therapy and mistake it for educational speechlanguage-hearing pathology. Teachers $\mathrm{T} 1$ to $\mathrm{T} 15$ are from the public school system and P16 to P25, from private ones. 


\section{Teachers who believe they know the educational speech-language-hearing pathologist's work}

Some teachers, such as T1, believe they know the educational speech-language-hearing pathologist's work. However, their answers reveal a generalized view that does not correspond to the specialty; instead, they encompass different fields of the speech-languagehearing sciences. It is also quite noticeable that the teachers constantly report they know the speechlanguage-hearing pathologist's work to a specific group - either teachers or students. This is indicated by $\mathrm{T} 19$, who also recognizes the importance of the speech-language-hearing follow-up for a child with autism spectrum disorder (ASD).

T1 "It's that work aimed at teachers and students... regarding speech, voice, hearing, vocal cord nodules. It is also related to learning and its difficulties, isn't it?"

T19 'Yes, I know it; it's the work done with children with speech difficulties, reading problems too. Actually, I know there is work with children with disabilities. Here at the school, for example, we have a child with autism; it would be interesting if he had a speech-language-hearing pathologist to follow up on him."

\section{Teachers who acknowledge they know little or in part the educational speech-language-hearing pathologist's work}

The teachers grouped into this category are mostly from the Municipal School System. Although they reported not fully knowing the educational speechlanguage-hearing pathologist's work, they tried pointing out characteristics that correspond to their field of work. The relationship with vocal aspects is quite frequent, as indicated by $\mathrm{T} 2, \mathrm{~T} 7$, and $\mathrm{T} 21$, because it is one of the teacher's main tools in the classroom. The relationship between the work of the speech-languagehearing pathologist and inclusive education is also frequent, present in the words of T7, T8, and T17. In their turn, T17 reports that, since they work in a small, neighborhood school, the access to speech-languagehearing pathologists is quite complicated, which contributes to their lack of knowledge of their work. On the other hand, the excerpt from T16's words indicates that their knowledge comes from research, with not much professional contact with such work.
T2 “No, I don't have much information. I know very, very little about it; but I suppose it has something to do with prevention, care of the voice, right? Since it is the tool we work with."

T6 "I've ever heard about it, but I suppose it aims at improving the student's performance in the classroom.... "Oh! I think they also work with deaf children and those with disabilities."

T7 "No... But they probably care for the teacher's voice, don't they?"

T8 "Well... no, I don't know. Actually, I think it has to do with deaf children, right? At a school where I used to teach there was a speech-language-hearing pathologist; they worked with Sign Language; they even had some equipment...But there isn't much of that nowadays, is there? It's very outdated."

T14 "I know the schools are required to have a speech-language-hearing pathologist, aren't they? To deal with the issue of children with speech errors, language delay... Usually, these speech-languagehearing pathologists offer them stimulation, I think that's it, right?"

T16 "I've only heard about it in part, from books, magazines, I know very little. Here where I work, not much is said about it. But I know it's related to children with speech errors, stuttering."

T17 "I don't know it, but it's probably related to children with disabilities. I don't know much about the field, you know? Especially because I work in a neighborhood school. We hardly ever have access to speech-language-hearing pathologists, not even to instruct parents to look for one..."

T18 "Right... educational speech-language-hearing pathologist? They work directly with the students, dealing with their education, don't they? But I don't know whether they work with these students away from school or at the school"

T21 "I know speech-language-hearing pathology for teachers, to care for our voice, you know? But I don't know if there's something aimed at the students." 


\section{Teachers who know and/or have already had some experience with the educational speech-language- hearing pathologist's work}

T3 reports knowing the educational speechlanguage-hearing pathologist's work from his/her own experience at a school where he/she used to work. In this case, it is pointed out that the speech-languagehearing pathologist verifies the need and then tries to train the teachers. In contrast, T10 refers to the work aimed more at preventing difficulties that may influence the educational process. This teacher also highlights the importance of the work that deals with the teachers' vocal aspects. T18, the only private school teacher, in his/her turn describes some interventions conducted by the speech-language-hearing pathologist at the school where he/she used to work sometime before.

T3 "The speech-language-hearing pathologist follows up on the children. At the school I used to work at, this pathologist first surveyed what was reported by the teachers, performed anamneses with the students, then trained us, and referred the children who needed specialized care."

T10 "I know there is a concern regarding the prevention of problems that come up in the school's routine and that make learning more difficult, especially those related to speech and writing... It often happens that a child comes to school, and we notice they have some hearing or speech problem, but then the family never looks for help, saying it's difficult for them. Oh, I also think the teacher should be attentively followed up as well since the voice is the main tool they have to work with. It wears out with time, doesn't it?"

T18 “l've already heard of speech-languagehearing pathologists. They have much to do with the children's speech, verbalization. I used to work at a school where they had a speech-language-hearing pathologist, it was quite interesting... I remember she would make some tests, some exercises in which the children had to speak vowels in different intonations, some exercises with the tongue, too. She would go to the classrooms with the children and ask them to vibrate and click the tongue... in some cases, she would see them individually, too."

\section{Teachers that do not know educational speech- language-hearing pathology}

Although $96 \%$ of the interviewed teachers had been graduated for more than six years, several reported not knowing educational speech-language-hearing pathology at all $(T 5, T 9, T 23)$. It was notorious in T13's words that, even though the speech-language-hearing pathology work aimed at vocal issues is more widely known, its educational branch is still unknown.

T5 "I've never heard of it!"

T13 "I know speech-language-hearing in general, you know? To care for the voice, vocal warm-up and cool-down; but no, l've never heard it with this name, educational speech-language-hearing pathology!"

T9 "No! l've never heard of this".

T23 "No, I haven't heard of it yet!".

\section{Teachers that have already had some experience with clinical speech-language-hearing therapy}

When asked about educational speech-languagehearing pathology, T4 related it to a work aimed at clinical practice, as he/she had already had speechlanguage-hearing follow-up.

T4 "I've already participated a long time ago, there was a center near the hospital (names the hospital). I had nodules on the right vocal cord, I had speechlanguage-hearing therapy for some months."

\section{DISCUSSION}

The children's first years at school coincide with the time when their language is widely expanding and the auditory skills, developing; these are highly important to school learning ${ }^{4,8,11}$. Nonetheless, the results obtained in the present study reveal that even experienced teachers, most of them with a postgraduate degree, as the ones that comprised this sample, have a considerably limited knowledge of important skills involved in the learning process. It is important to highlight that, along with other health professionals that need to follow up on the children's growth and development, the teachers and others in the faculty are also responsible for promoting the development of these skills at school ${ }^{2,9}$.

On the other hand, the Brazilian educational scenario points to worrying indexes regarding the students' low school achievements, especially at public 
schools and in elementary school ${ }^{8}$. This demonstrates the importance of revising and discussing aspects related to the teaching methods and the important role of the cognitive and linguistic skills to learning to read and write, including such topics in the teachers' training ${ }^{7-9,11}$.

School learning involves different skills, such as central auditory processing - a relationship that has been frequently discussed in the literature ${ }^{5,8,12}$. In the present study, most of the teachers are unfamiliar with the skills attributed to the central auditory system, although they recognize that the auditory processing disorder (APD) may be associated with learning and language development. Reis, Dias, and Boscolo ${ }^{5}$ researched to verify the teachers' knowledge of the relationship between central auditory processing and school learning, before and after a workshop with speech-language-hearing guidelines. It was perceived in it that their limited knowledge of the APD, as well as their difficulty to identify it and establish a relationship with the learning problems presented by the students, can maintain and linger the student's limitations.

As for the present study, all the interviewed teachers notice the influence of language development on learning to read and write. However, most of them do not feel ready to observe the aspects related to their students' speech and language. The study conducted by Rosal et al. ${ }^{12}$, whose objective was to investigate the contribution of phonological awareness and rapid serial naming to children's first learning to write, reinforces the importance of developing phonological abilities while still in kindergarten because, if such abilities are stimulated early, the child will start the process of learning to read and write with a greater understanding that will aid in such process.

Comparing the answers between public and private school teachers did not reveal significant differences in 15 out of the 16 questions analyzed. There seems to be no important difference between these two work settings.

The interviewed teachers usually refer the children with speech or language problems to specialists although they do not feel prepared to observe such aspects. Considering that the demand in most of the speech-language-hearing services is greater than they can attend, the teachers need to know enough to identify the problems and adequately refer them. Hence, education professionals need to acquire the necessary information about changes that may explain certain learning difficulties, so they can improve school development ${ }^{5}$.

Based on the data collected, it is verified that all the teachers believe that knowledge of the field of language and hearing would be helpful for them to early identify students with signs of learning difficulties. It is known that children with impaired oral language development, phonological awareness, or grapheme-phoneme relationship can be considered at risk of reading or writing difficulty ${ }^{13}$. Learning disorders are caused by deficits in the central nervous system. They can be responsible for changes in the cognitive and language processing, directly influencing the ability to efficiently maintain, process, or transmit information ${ }^{14}$.

The teachers often reported a difficulty to recognize the limits of the educational speech-language-hearing pathologist's work, including a practice more aimed at rehabilitation and therapy. The relationship with clinical practice, frequently pointed out in the words of the interviewed teachers, can be explained by the development of speech-language-hearing sciences in Brazil as health science, specialized in changes that people had in the normal communication standards. In Australia, the United Kingdom, and Brazil, for instance, most speech-language-hearing pathologists belong to the Departments of Health, whereas teachers belong to the Departments of Education'.

In a research ${ }^{15}$ conducted with undergraduate speech-language-hearing students regarding educational speech-language-hearing pathology according to their theoretical-practical experiences, it was noticed that a great part of the answers had a clinical/preventive bias. To solidify and strengthen educational speechlanguage-hearing pathology, this professional also needs to define and occupy their place as one who belongs at school, who understands the intervention possibilities in the teaching process, for the other professionals in that setting to understand their role.

In the present study, the work of the speechlanguage-hearing pathologist associated with inclusive education also received some comments - once again revealing the relationship with the aspects that deal with changes. This in turn can be also explained by the noteworthy mobilization of education professionals around the theme of inclusion. The speech-languagehearing pathologists in the educational setting can have the role of a mediator between the child and the school, promoting in the student a better communicative development ${ }^{16}$. Moreover, they propose strategies along 
with the faculty to potentialize the teaching/learning process 4 .

The interviewed teachers frequently relate the educational speech-language-hearing pathologist's work with the vocal issues they present. It is a consensus in the national and international literature that teaching is an activity with a high risk of occupational voice disorders. The teacher's voice is a common theme in research, especially as this is the professional that most often gets sick for vocal issues ${ }^{17}$.

The teachers proved to have limited knowledge of educational speech-language-hearing pathology. Likewise, in research by Fernandes, Lima, and Silva ${ }^{18}$, whose objective was to analyze kindergarten teachers' perception of the speech-language-hearing pathologist's work inside the school, it was observed that the teachers relate such practice to the children with speech difficulties and auditory changes, as one who will solve such problems.

Despite the limited knowledge, the teachers acknowledge that such work is beneficial to their students' development. Although they are different, the teachers' and speech-language-hearing pathologists' standpoint and knowledge regarding learning and language development are mutually complementary ${ }^{1}$. The data from the research by Fernandes, Lima, and Silva ${ }^{18}$ are similar to the information found in the present study. It is thus notorious that the education professionals' lack of knowledge of the educational speechlanguage-hearing pathologist's work is a barrier that needs to be overcome. To help solidify this specialty, speech-language-hearing pathologists also need to identify themselves as professionals that belong to school, understanding their field of practice.

Lastly, it is important to highlight that the present study was conducted with a small sample of professionals, in public and private educational settings in Recife. Considering the decentralized initial stages of basic education, which are administered by the municipality ${ }^{7}$, other places may have different scenarios. Hence, further studies must be conducted to compare the various realities from different cities and establish a national panorama.

\section{CONCLUSION}

In general, the teachers recognize the importance of language and auditory skills to learning, although they do not feel prepared to deal with these aspects at school. On the other hand, they deem it essential to get acquainted with tools that will help them identify children presented with learning disorders. Regarding educational speech-language-hearing pathology, the interviewed teachers are unfamiliar with their specific work, despite having an overall knowledge of what a clinical speech-language-hearing pathologist does. The teachers most acquainted with the specialty are those who have already had experience with a speechlanguage-hearing pathologist's work in an educational context. No important differences were observed between the answers of public-school teachers and those of the private system. Greater investments need to be made in the teachers' permanent training regarding the theme approached in this study.

\section{REFERENCES}

1. Glover A, McCormack J, Smith-Tamaray M. Collaboration between teachers and speech and language therapists: Services for primary school children with speech, language and communication needs. Child Language Teaching and Therapy. 2015;31(3):363-82.

2. BRASIL. Portaria $n^{\circ}$ 1.130. Política Nacional de Atenção Integral à Saúde da Criança (PNAISC) no âmbito do Sistema Único de Saúde (SUS). 2015.

3. Conselho Federal de Fonoaudiologia. Resolução $\mathrm{N}^{\circ} 387 / 2010$. Dispõe sobre as atribuições e competências do profissional especialista em Fonoaudiologia Educacional reconhecido pelo Conselho Federal de Fonoaudiologia, alterar a redação do artigo 10 da Resolução CFFa no $382 / 2010$, e dá outras providências.

4. Celeste LC, Zanoni G, Queiroga B, Alves LM. Hearing and Speech Sciences in Educational Environment Mapping in Brazil: education, work and professional experience. CoDAS. 2017;29(1):1-7.

5. Reis TG, Dias RF, Boscolo CC. Conhecimento de professores sobre processamento auditivo central pré e pós-oficina fonoaudiológica. Rev. Psicopedag. 2018;35(107):129-41.

6. Sobreira ACO, Capo BM, Santos TS, Gil D. Speech and language development in hearing impairment: two- case report. Rev. CEFAC. 2015;17(1):308-17.

7. BRASIL. Ministério da Educação. Secretaria de Alfabetização. Política Nacional de Alfabetização/ Secretaria de Alfabetização (PNA). - Brasília: MEC, SEALF, 2019.

8. Zorzi J. Programs for the development of cognitive and linguistic skills involved in literacy and spelling: methodological proposal. Rev. Psicopedag. 2018;35(108):340-7. 
9. Moura TFOR. Visão de professores e equipe de saúde sobre aatuação da fonoaudiologia na educação infantil [Dissertação]. Campinas (SP): Universidade Estadual de Campinas, Faculdade de Ciências Médicas; 2016.

10. Bardin L. Análise de conteúdo. $3^{\mathrm{a}}$ reimp. da $1 \underline{\underline{a}}$ ed. São Paulo: Edições 70, 2016.

11. Masuyama PMK, Rinaldi RP. Prospects of a collaborative education: interweave between education and speech therapy. Colloquium Humanarum. 2016;13(n. Especial):417-23.

12. Rosal AGC, Cordeiro AAA, Silva ACF, Silva RL, Queiroga BAM. Contributions of phonological awareness and rapid serial naming for initial learning of writing. Rev. CEFAC. 2016;18(1):74-85.

13. Silva NSM, Crenitte PAP. Performance of children at risk for reading difficulties submitted to an intervention program. CoDAS. 2016;28(5):517-25.

14. Germano GD, Brito LB, Capellini SA. The opinion of parents and teachers of students with learning disorders regarding executive function skills. Rev. CEFAC. 2017;19(5):674-82.

15. Sanabe JG, Guarinello AC, Santana AP, Berberian AP, Massi G, Bortolozzi KB et al. Speechlanguage pathology undergraduates' views about educational speech-language pathology from their theoretical and practical experiences. Rev. CEFAC. 2016;18(1):198-208.

16. Queiroga BAM, Zorzi JL, Garcia VL. Fonoaudiologia Educacional: reflexões e relatos experiência. Brasília: Editora Kiron, 2015.

17. Souza RC, Masson MLV, Araújo TM. Effects of the exercise of the semi-occluded vocal tract with a commercial straw in the teachers' voice. Rev. CEFAC. 2017;19(3):360-70.

18. Fernandes DMZ, Lima MCMP, Silva IR. The perception of kindergarten teachers about the speech therapist work at school. Distúrb. Comum. 2017;29(1):86-96. 